\title{
Microscopic Characterization of the Thermal Evolution of Stainless Steel Coatings Sputter-deposited onto WC Particles
}

\author{
C.M. Fernandes, ${ }^{*}$ A.M.R. Senos* and M.T. Vieira** \\ * Department of Ceramics and Glass Engineering, CICECO, University of Aveiro, 3810-193 \\ Aveiro, Portugal \\ ** ICEMS - Mechanical Engineering Department, Polo 2 of University of Coimbra, 3030-201 \\ Coimbra, Portugal
}

The hardmetal composites are generally produced from powders of tungsten carbide (WC) and of metal elements, belonging to group 8-10 of the periodic table, which are mixed together by wet milling. News processes, alternatives to milling, have been developed, aiming a higher uniformity of the metallic binder distribution in WC based composites, together with other technological benefits $[1,2]$. One of those methods consists of the sputter deposition of metal binder onto the WC powder leading to powder particles coated with the metallic elements. The particles coating showed to be chemically and morphologically very uniform and possesses a nanocrystalline structure and improved surface properties, such as powder's flowability, pressing behaviour, sinterability and thermal reactivity [3].

In this study stainless steel (SS) 304 AISI coatings (10 wt.\%) have been sputter-deposited onto WC powder particles (average particle size of $9 \mu \mathrm{m}$ ). Figs.1-a and 1-b present SEM micrographs of WC powder particles before and after the sputter-deposition, respectively. The roughening of the particle surface after sputtering, in Fig. 1-b), comes from the columnar growth and nanocrystalline morphology of the SS coating (Fig. 1-b, inset). The roughening is observed on all particle surfaces. Accordingly, the cross section of a coated particle (Fig. 1-c) shows a thin coating layer $(\sim 200 \mathrm{~nm})$, surrounding the WC core particle. These observations clear show that a good coverage of the particle surfaces and a high uniformity in the distribution of the SS binder in the whole compact can be achieved by the sputtering technique.

The SS coating was observed to keep covering the $\mathrm{WC}$ particles after heating up to $600^{\circ} \mathrm{C}$, with some reduction of its roughness. However, at higher temperatures, the uniformity of the binder distribution will be something lost as can be observed in the SEM micrograph of a sintered compact (obtained from the coated powder after pressing and sintering at $1325^{\circ} \mathrm{C}$, during $3 \mathrm{~h}$ at 20 $\mathrm{Pa}$ ), presented in Fig. 2. The X-ray maps of elements in the same figure shows that $\mathrm{Fe}$ and $\mathrm{Cr}$ are now concentrated in some regions among the WC grains. Ni is present in lower amount than $\mathrm{Fe}$ and $\mathrm{Cr}$ and it isn't so clear the concentration of this element in those regions. Although the regions that contain most of the binder elements are well dispersed in the compact, the original distribution of these elements in thin coatings surrounding the particles was effectively lost. The lost of uniformity is caused by viscous deformation of the metallic binder, when the eutectic temperature is attained $\left(\mathrm{T} \geq 1150^{\circ} \mathrm{C}\right)$ and by the reaction between the $\mathrm{WC}$ and the metallic elements of the binder, forming $\left(\mathrm{T}>800^{\circ} \mathrm{C}\right)$ a carbide eta-phase, $(\mathrm{M}, \mathrm{W})_{6} \mathrm{C},[3]$. In the sintered sample, almost all the binder elements are contained in this phase with an approximate stoichiometry of $\left(\mathrm{Fe}_{2.3} \mathrm{Ni}_{0.3}\right)\left(\mathrm{Cr}_{0.6} \mathrm{~W}_{2.8}\right) \mathrm{C}$, as determined by EDS (Table 1) and confirmed by 
electron microprobe analysis (EMPA). Additionally, XRD analysis showed that this phase possesses a nanocrystalline structure with $26 \mathrm{~nm}$ of cristallite size.

Interesting mechanical properties were found in these samples, high hardness, together with a good toughness [4], despite the fact that almost all the metallic elements are contained within the eta-phase, a hard but non-ductile, fragile phase. These unexpected properties were attributed to the relative improvement of the uniformity of the binder distribution, when compared with conventional prepared samples, and to the nanocrystalline structure of the eta phase, remnant of the original nanostructure of the coating [4].

\section{References:}

[1] C. Vahlas, B. Caussat, P. Serp, G. Angelopoulos, Mat. Sci. Eng. R 53 (2006) 1.

[2] C.M. Fernandes, A.M.R. Senos, M.T. Vieira, Surf. Coat. Tech 176 (1) (2003) 103.

[3] C.M. Fernandes, A.M.R. Senos, M.T. Vieira, Int. J. Refr. Metals Hard Mater. 21 (2003) 147.

[4] C.M. Fernandes, A.M.R. Senos, M.T. Vieira, J.V. Fernandes, to be published.
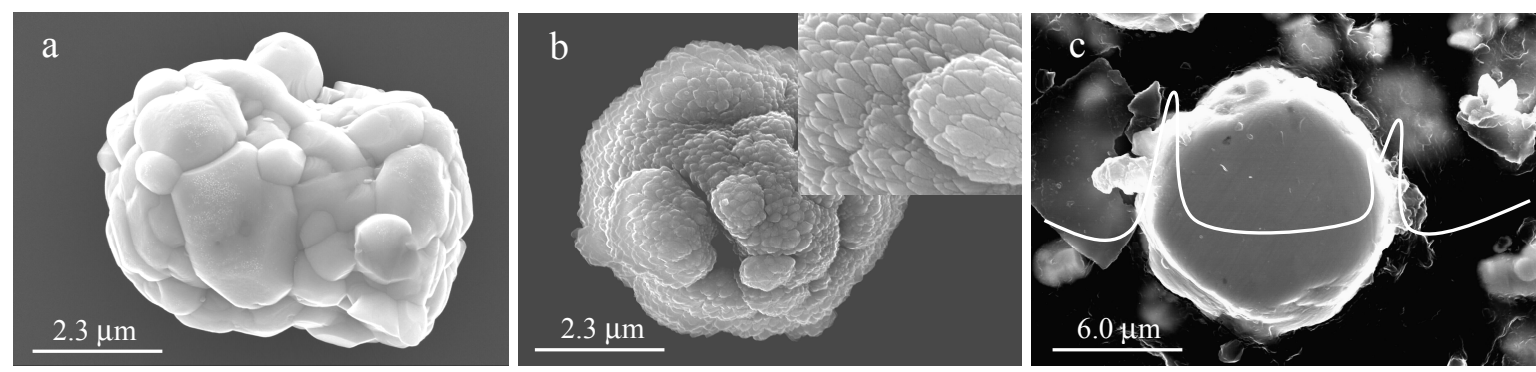

Fig. 1. SEM micrographs taken from (a) non-coated WC particle surface (b) coated WC particle surface and (c) cross section of a coated particle with the iron concentration profile.

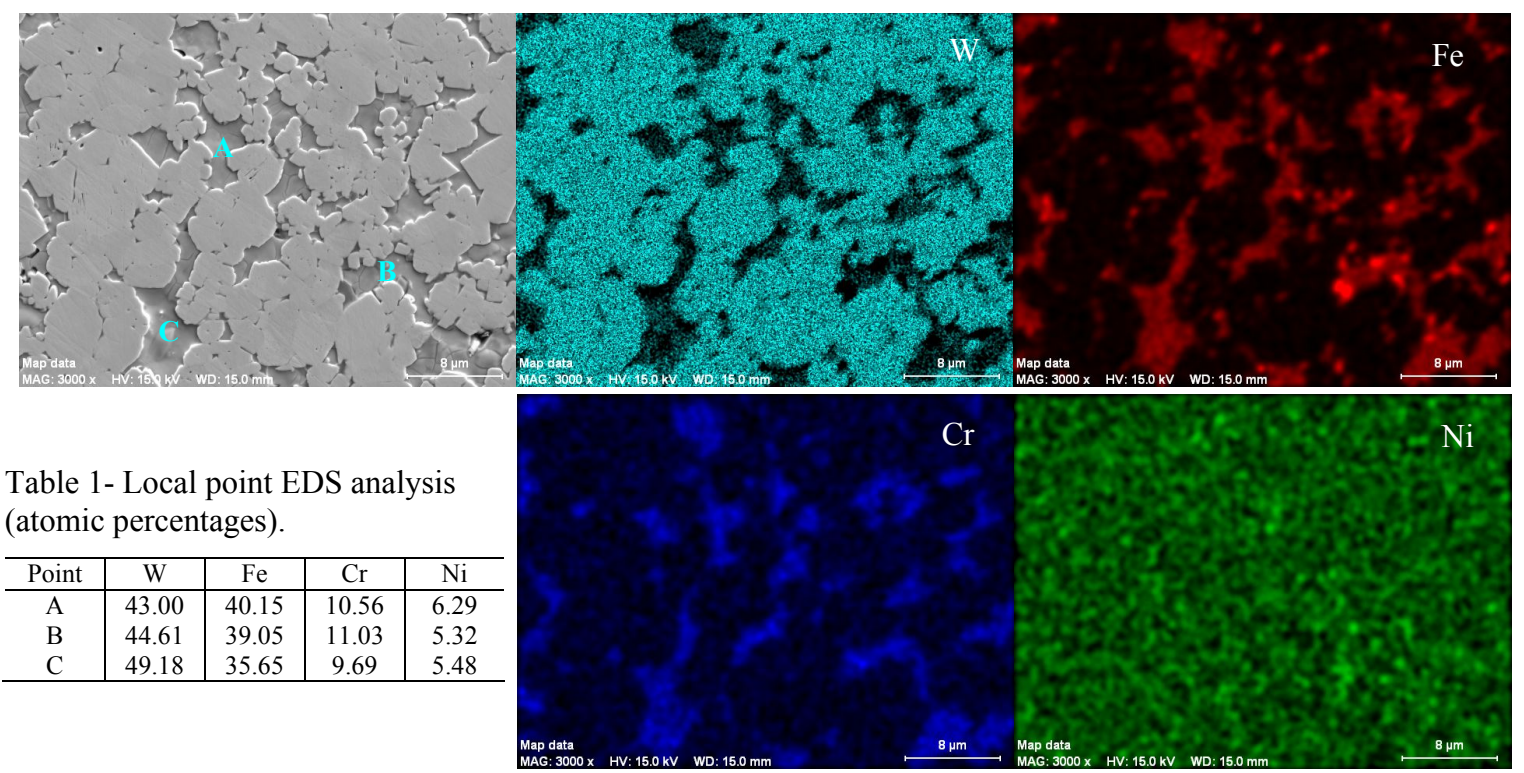

Fig. 2. SEM micrograph of a sample sintered at $1325^{\circ} \mathrm{C}$ and respective X-ray maps of elements. 